\title{
The Sexual Cascade and the Rise of Pre-Ejaculatory (Darwinian) Sexual Selection, Sex Roles, and Sexual Conflict
}

\author{
Geoff A. Parker \\ Department of Evolution, Ecology and Behaviour, Institute of Integrative Biology, University of Liverpool, \\ Liverpool L69 7ZB, United Kingdom \\ Correspondence: gap@liverpool.ac.uk
}

After brief historic overviews of sexual selection and sexual conflict, I argue that pre-ejaculatory sexual selection (the form of sexual selection discussed by Darwin) arose at a late stage in an inevitable succession of transitions flowing from the early evolution of syngamy to the evolution of copulation and sex roles. If certain conditions were met, this "sexual cascade" progressed inevitably, if not, sexual strategy remained fixed at a given stage. Prolonged evolutionary history of intense sperm competition/selection under external fertilization preceded the rise of advanced mobility, which generated pre-ejaculatory sexual selection, followed on land by internal fertilization and reduced sperm competition in the form of postcopulatory sexual selection. I develop a prospective model of the early evolution of mobility, which, as Darwin realized, was the catalyst for pre-ejaculatory sexual selection. Stages in the cascade should be regarded as consequential rather than separate phenomena and, as such, invalidate much current opposition to Darwin-Bateman sex roles. Potential for sexual conflict occurs throughout, greatly increasing later in the cascade, reaching its peak under precopulatory sexual selection when sex roles become highly differentiated.

Sexual selection and sexual conflict are vast Sfields in evolutionary biology; when possible, here, I refer to reviews. I begin with brief general historic overviews of sexual selection and sexual conflict; more detail can be found in Andersson (1994), Simmons (2001), Chapman et al. (2003), and Arnqvist and Rowe (2005). Much of the current state of the field of sexual conflict is covered in this collection.

My principal aim, however, is to outline how sexual selection and sexual conflict have changed through evolutionary time, from mostly gamete competition in early unicellular eukaryotes, intense sperm competition in ancestral sessile and relatively immobile organisms, to both pre-ejaculatory (Darwinian) and postejaculatory sexual selection. These transitions in the evolution of sexual strategy arise as logical consequences whenever certain successive conditions are met, and together form what may be termed the "sexual cascade."

Editors: William R. Rice and Sergey Gavrilets

Additional Perspectives on The Genetics and Biology of Sexual Conflict available at www.cshperspectives.org

Copyright (C) 2014 Cold Spring Harbor Laboratory Press; all rights reserved; doi: 10.1101/cshperspect.a017509

Cite this article as Cold Spring Harb Perspect Biol 2014;6:a017509 
G.A. Parker

\section{HISTORIC OVERVIEW: SEXUAL SELECTION}

\section{Precopulatory Sexual Selection}

Darwin (1871, p. 256) defined sexual selection as depending "on the advantage which certain individuals have over other individuals of the same sex and species, in exclusive relation to reproduction." Although his definition clearly embraces all possible aspects of sexual selection, Darwin's evidence and discussions related exclusively to competition over mating and ejaculation. The past $40-50$ years have seen massive research efforts devoted to this subject. Darwin's two major categories of pre-ejaculatory sexual selection (male combat and female choice) are now described in all evolutionary texts. The monograph by Andersson (1994) gives an excellent survey of all but the last two decades.

Interest and controversy surrounded sexual selection for half a century after Darwin, generating both detailed surveys (e.g., Richards 1927) and notable conceptual advances (Fisher 1930), but attention faded after Huxley's influence in the 1930s (Huxley 1938a,b). Despite the occasional inspirational study (e.g., Jacobs 1955), the subject languished for almost three decades, probably because of the (implicit) group/species selection interpretations of adaptation prevailing throughout that time. The notable exception was Bateman's (1948) now classic study of Drosophila melanogaster, which he used to support his argument that sexual selection arises because male fitness typically increases more steeply with number of matings with different females than female fitness mating with different males, a fact that (following Darwin) he attributed ultimately to anisogamy. He used this to explain why males show "undiscriminating eagerness" and females "discriminating passivity," behavioral characteristics of sexual selection stressed by Darwin (1871) and considered to be supported by general observation. The relation between fitness and number of matings is now termed the "Bateman gradient," and the predictions surrounding this classic view of sexual selection have been termed the DarwinBateman paradigm or DBP (Dewsbury 2005).
Despite the major early conceptual advances after Darwin made by Fisher (1930), an explosion of interest, including attention to Bateman's ideas, gained impetus much later during the behavioral ecology revolution of the 1970s (Parker 2006a), although the first signs came earlier. Maynard Smith's (1958) essay helped to clarify the different effects of natural and sexual selection, which were becoming confused, and Fisher's (1930) work was republished in 1958. For sexual selection by female choice, Fisher had proposed (1) that females showing a preference for males with traits indicating their biological fitness ("indicators"; see Andersson 1994) would be favored, which (2) leads to positive feedback between the gene for the preferred male trait and the gene for the female preference ("Fisher's sons effect"), accelerating fixation of both genes, and (3) female choice may exaggerate the development of the male trait beyond its natural selection optimum (the "runaway" process) until natural selection finally prevents further development. Fisher's last research student, Peter O'Donald, pioneered population genetic models of female choice (O'Donald 1962, 1980), concluding that conditions for runaway were restrictive. However, notably, more optimistic advances concerning Fisher processes were made by Lande (1981; see also Kirkpatrick 1982). "Indicators" include cues of "good genes" or immediate female benefits such as good male territories or parenting (e.g., Williams 1966; Orians 1969; Trivers 1972), "handicaps" that signal "good genes" (Zahavi 1975; Grafen 1990), and brightness of male coloration correlating with parasite resistance (Hamilton and Zuk 1982). Andersson (1994) gives an excellent review of the historical development of these ideas.

Male-male competition for matings has attracted less theoretical attention than female choice, possibly because it is simpler and less interesting conceptually. Trivers' (1972) proposal that relative parental investment (PI) determines the intensity of sexual competition undoubtedly catalyzed the sudden interest in sexual selection that began in the 1970s. It was followed by suggestions that the operational sex ratio (OSR) (Emlen and Oring 1977) or relative 
potential rates of reproduction (PRR) (CluttonBrock and Vincent 1991) represented the key index. More recently, emphasis has been placed on the difference in variance of reproductive success of the sexes (Shuster and Wade 2003), an index expressing the opportunity for sexual selection and related to Bateman's (1948) original predictions. All measures (PI, OSR, PRR, and relative variance in reproductive success) are likely to covary with the relative "times in" and "times out" of the mating pool of the two sexes (Clutton-Brock and Parker 1992; see Parker and Birkhead 2013) and have good reasons to correlate with sexual selection intensity (Jennions and Kokko 2010; Kokko et al. 2012; Parker and Birkhead 2013), although debate still continues over exactly what measure best reflects the intensity of sexual selection (reviewed in Parker and Birkhead 2013).

Qualitative evidence for male-male competition has always been very strong compared with female choice. My PhD studies of dung flies, published mostly in 1970, may represent the first attempt to validate this aspect of sexual selection quantitatively (reviewed in Parker 1978a,b, 2006a). Field observations fitted well with predictions based on competitive optimization models, suggesting that sexual selection could indeed be the dominant selective force shaping male reproductive behavior. Males behaved so as to maximize fertilization rate given that other males do the same, that is, their behavior patterns appeared to be evolutionarily stable strategies (ESSs) (sensu Maynard Smith and Price 1973; Maynard Smith 1982) set by the selective pressure of intramale competition (reviewed in Parker and Pizzari, in press). There can be little doubt that intrasexual selection has played a major part in determining male mate searching, contest, and mate-guarding strategies, something that has been rather overshadowed in recent decades by the focus on female choice.

\section{Postcopulatory Sexual Selection}

It is interesting that Darwin dismissed lower invertebrates: "The lowest classes will detain us for a very short time...." (Darwin 1871, p. 300), considering them to be unaffected by sexual selection: "In the lowest classes the two sexes are not rarely united in the same individual, and therefore secondary sexual characters cannot be developed. In many cases in which the two sexes are separate, both are permanently attached to some support, and the one cannot search or struggle for the other.... Hence in these classes, such as the Protozoa, Coelenterata, Echinodermata, Scolecida, true secondary sexual characters do not occur; and this fact agrees with the belief that such characters in the higher classes have been acquired through sexual selection, ..." (Darwin 1871, p. 321). Darwin debated why bright coloration occasionally occurs in some sessile or relatively immobile invertebrates, concluding this to be the product of natural rather than sexual selection. Although he rejected the relatively mobile annelids and cephalopod mollusks as candidates for sexual selection, he devoted much discussion to the various arthropod taxa, particularly in the insects, in which copulation is often well developed and male fighting apparatus and bright coloration sometimes apparent.

Arthropods aside, Darwin thus gave virtually all his attention to vertebrates, particularly those with copulation and internal fertilization. He did not mention competition between ejaculates or massive male gametic expenditure in his "lowly organized" sessile or relatively immobile animals. I argue here that such stages played a major role, with their high testes expenditure because of competition between ejaculates, in the cascade of events in the evolution of sexual strategy that culminated in precopulatory sexual selection that Darwin so brilliantly perceived and described in 1871. That he so positively dismisses these taxa suggests that he did not suppress insights into ejaculate competition simply because of the sensitivities of Victorian culture. Remarkably, "Darwin probably never made the intellectual leap that would have allowed him to identify the possibility of postcopulatory sexual selection" (Birkhead 2010) or competition between ejaculates in general.

It is now well appreciated that sexual selection does not end when mating begins. Birkhead (2010) gives an excellent account of the historic 


\section{G.A. Parker}

aspects of postcopulatory sexual selection. My review of sperm competition in insects (Parker $1970)$ is claimed to have stimulated development of the field of postcopulatory sexual selection (e.g., Birkhead 2000, 2010; Simmons 2001; Eberhard 2009). Since 1970, enormous amounts of research, both empirical (e.g., Smith 1984; Birkhead and Møller 1992, 1998; Simmons 2001) and theoretical (reviewed in Parker and Pizzari 2010) have been devoted to the topic. Later, attention also focused on female control of fertilizations, that is, "cryptic female choice" in the form of sperm selection or ejaculate manipulation (Thornhill 1983; Eberhard $1985,1996,2009)$. Sperm competition is now seen as the postejaculatory analog of Darwinian male-male competition for mating and cryptic female choice, the analog of Darwinian female choice of males before mating.

Postcopulatory sexual selection, in fact, encompasses adaptations both during and after copulation (Eberhard 2009). Although categorization into pre- and postcopulatory sexual selection serves a useful purpose, it presents problems for the many externally fertilizing taxa in which copulation is lacking; "pre- and postejaculatory" are more general terms. Competition among ejaculates will normally be a strong selective force in external fertilizers, including those that are sessile and weakly mobile (Levi$\tan 2010$ ). Failure to appreciate this not only was an oversight by Darwin, but has also impeded a full understanding of the succession of evolutionary events (the "sexual cascade") that generated internal fertilization and precopulatory sexual selection.

\section{HISTORIC OVERVIEW: SEXUAL CONFLICT}

A detailed history of the field of sexual conflict can be found in Arnqvist and Rowe (2005). "Battle of the sexes" concepts (the notion that males and females have conflicting interests) go back into history and usually relate to the immediate behavior associated with conflicts between the sexes. In evolutionary biology, sexual conflict concerns instances in which the evolutionary interests of males and females are different (Parker 1979) and arises very commonly out of sex- ual selection when a mutation causes strategic changes that would increase fitness in one sex, but decrease fitness in the other sex (a sexually antagonistic mutation). In fact, sexual conflict concepts can be applied to all anisogamous sexual systems (Schärer et al. 2014) Hermaphrodites combine male and female in one individual, and sexual conflict operates differently in sequential and simultaneous hermaphrodites (Schärer et al. 2014). At the level of nuclear genes, conflict can be interlocus if it concerns traits determined by different loci or intralocus if it concerns a trait determined by alleles at a single locus (Rice and Holland 1997; Parker and Partridge 1998). Cytoplasmic genetic elements are maternally inherited and require a different logic (e.g., Zeh 2004; Hurst and Frost 2014). For interlocus conflict, a sexually antagonistic mutation will spread unless a counterstrategy evolves to prevent it at a locus expressed in the other sex. Various definitions have been proposed (see Arnqvist and Rowe 2005; Kokko and Jennions 2014), but it is important to note that sexual conflict in evolutionary biology relates to conflict in evolutionary time, which may or may not be manifest in the behavior observed in male-female interactions.

Although Darwin (1871) appears not to have discussed sexual conflict directly, he was well aware that sex-limited inheritance could relate to different selective forces acting on males and females. For example, he envisaged that adult female size was often increased by selection to produce more ova and cryptic female coloration could reflect camouflage against predators (i.e., because of natural selection), whereas increased male size, weaponry, and coloration often reflected the result of sexual selection. Darwin-Bateman notions of indiscriminate eagerness in males and discriminating passivity in females also hint at mating conflict.

The concept that a gene may be beneficial in one sex but costly in the other was appreciated for many decades by population geneticists (e.g., Fisher 1931, p. 363), but little detailed discussion of the opposing interests of the sexes can be found before 1970 (Arnqvist and Rowe 2005); with rare exceptions, the prevailing view was that reproduction is an exclusively cooper- 
ative venture between the sexes. The modern rise of the concept of sexual conflict, as with sexual selection, is linked to the behavioral ecology revolution that had its roots in the late 1960s and exploded in the 1970s (Parker 2006a). During this period, the concept became quite widespread among those involved. Williams (1966) discussed an "evolutionary battle of the sexes" in which males may be adapted to overcome female resistance to mating, which would generate counteradaptation in females. (Williams' index includes the term "sexual conflict," but in the sense of intrasexual competition between males.) Clear expositions in the biological literature appear to be those by Trivers (1972) and Dawkins (1976) (see also Dawkins and Krebs 1979).

Arnqvist and Rowe (2005) have claimed that an important early foundation was my paper (Parker 1979) on sexual conflict and sexual selection, which was delayed in press (for historic accounts, see Arnqvist and Rowe 2005; Parker 2006a, 2010, 2013). It had been stimulated by my dung fly research in the late 1960s in which I analyzed male and female interest separately and appreciated that they could often be in conflict. Realizing that this had general implications, the final paragraph of my sperm competition review concluded with (Parker 1970, p. 559):

\begin{abstract}
The female cannot be regarded as an inert environment in and around which this form of adaptation (male adaptation to sperm competition) evolves. Supposing, for example, a mating plug reduces a female's reproductive rate, this natural selection disadvantage will affect both male and female. Provided that the plug confers a sexual selective advantage on the male, which outweighs its natural selective disadvantage, it should evolve or be maintained. Resultant modifications within the female to prevent or reduce the disadvantageous effects of the plug might be expected; these adaptations may conflict with the line of adaptation in the male sex. The female, however, is not isolated from intramale selection because a female mating with a male possessing a character of sexual selective advantage will gain if the character is present in her male offspring.
\end{abstract}

This foreshadowed my 1979 analysis, which began by investigating the parameter space (the "conflict zone" or "battleground") within which sexual conflict will apply, given that the male and female have shared offspring (see also Andrés and Morrow 2003; Parker 2006b). Consider a mutant gene that increases a male's fitness through sexual selection, but has a collateral cost via the female affecting their shared offspring. If the cost is too high, there is no conflict, and the gene will not spread. If the cost is sufficiently low and the benefit high, the gene will spread, and so will a gene that causes females to prefer to mate with a mutant male. But for a large parameter space, there will be conflict; the male trait is favored, but so is female resistance to males with the trait, that is, the character is in male, but not female, interests. The analysis went on to define and analyze biological cases and conflict zones in which sexual conflict was likely, and two simulation models to investigate conflict resolution, one of which resulted in continual cycling of coevolutionary strategies ("unresolvable evolutionary chases").

This paper attracted little interest and, as a subject area, sexual conflict remained inconspicuous until the mid-1990s. Although exceptions during this period were few (see Arnqvist and Rowe 2005), some were notable. For example, laboratory studies showed significant costs to D. melanogaster females inflicted by males during mating (Partridge et al. 1986); these result from male accessory gland proteins, many of which appear to benefit males, but conflict with female interests (reviewed by Simmons 2001 and Chapman et al. 2003). Field studies also occasionally provided strong evidence for sexual conflict (a notable example is Davies 1992).

A surge of activity, however, occurred in the mid-1990s. Key players were Bill Rice and his student Brett Holland in America, Göran Arnqvist in Sweden, and Locke Rowe in Canada, although many others contributed. Arnqvist began his study of sexual conflict by working on mating systems of water striders, Gerris (Arnqvist 1989), as did Locke Rowe (Rowe 1992). They were quick to collaborate (Rowe et al. 1994) and produced strong empirical evidence of a coevolutionary arms race between male-clasping devices to overcome female resistance, and female adaptations to aid in male rejection (Arnqvist 


\section{G.A. Parker}

and Rowe 1995). In addition to their independent contributions to sexual conflict, their collaborations, culminating in their major monograph (Arnqvist and Rowe 2005), have both notably advanced and consolidated the field.

Bill Rice came to the subject through evolutionary genetics; his early theoretical work showed that sex chromosomes assist sexual dimorphism evolution by enabling genes coding for sexually dimorphic traits to accumulate on the X (or Z) chromosome (Rice 1984). He used genetic markers and experimental evolution to create a new sex-determining locus in D. melanogaster and elegantly showed that, as predicted, genes detrimental to the homogametic sex accumulated close to this locus (Rice 1992). Appreciating that male and female interests often could not be satisfied simultaneously and that this may generate sexually antagonistic coevolution (a form of intraspecific Red Queen) (Rice and Holland 1997; Holland and Rice 1998), Rice (1996) showed by experimental evolution that when female D. melanogaster were prevented from coevolving with males, males quickly adapt, generating high costs to females. Holland and Rice (1999) showed that in D. melanogaster populations in which monogamy was enforced during experimental evolution, males evolved to be less harmful to females, which evolved to be less resistant to male-induced harm. Gavrilets (2000) devised an important formal model of "chase away" coevolution similar to that envisaged by Rice and Holland (1997) and Holland and Rice (1998), showing that this has the potential to drive speciation (although this depends on how conflict is resolved) (Parker 1979; Parker and Partridge 1998).

In the past decade or so, opposition to sexual conflict interpretations has been spearheaded by Bill Eberhard (e.g., Eberhard 2005), who proposed that apparent behavioral conflict is often in female interests and represents a mechanism by which the female filters out (rejects) lower-quality males and "gains by losing" to persistent males of high mating advantage because they generate high fitness progeny. This catalyzed debate on the importance of sexual conflict (see Hosken and Snook 2005 and arti- cles in the same supplement; Tregenza et al. 2006 and articles in the same theme issue), the prevailing view supporting the ubiquity of sexual conflict. Sexual conflict has, by now, become an important and currently vigorous field in evolutionary biology.

\section{EVOLUTION OF SEXUAL STRATEGIES: THE SEXUAL CASCADE}

The various evolutionary adaptations surrounding sexuality have presented a formidable challenge for evolutionary biologists and many, from meiosis to sexual selection and sexual conflict, continue to generate debate. Here and elsewhere (Parker and Pizzari, in press), a deductive approach is developed that seeks to explain sexuality as a sequence of events within a causal framework. It is important to distinguish between irreversible evolutionary transitions that are ubiquitous and fixed in most extant advanced animal taxa and more labile transitions that can be more readily reversed by ecological changes. The primary sexual step of meiosis and syngamy leads predictably to gamete competition and (especially as organismal complexity increases) to the evolution of two sexes (anisogamy), which generates unitary sex ratios. Ancestral forms of sexual selection (gamete competition and selection) would have been prevalent in early external fertilizers. With the evolution of mobility and behavioral complexity, copulation and "traditional" sex roles emerge inevitably in most anisogamous systems lacking parental care (i.e., most animal species). However, parental care of the zygote is a much more labile transition that allows deviations from traditional sex roles through the evolution of paternal investment.

During this evolutionary succession (the "sexual cascade"), the opportunity for different episodes of sexual selection changes dynamically, and alternative stable states occur at many steps. After the ancestral phase of gamete and sperm competition under external fertilization, precopulatory sexual selection eventually follows as a result of such features as multicellularity, the unity sex ratio, enhanced mobility and increased behavioral capacity for male- 
male competition, and the evolution of internal fertilization and is associated with a reduction in the strength of postcopulatory sexual selection and an associated increase in precopulatory sexual selection, with a consequent higher differentiation of male and female sexual strategies. There is a notable logical compulsion in this sequence of events that flows inevitably from the early evolution of meiosis and gamete formation and eventually results in sex-role differentiation and its associated conflicts (Parker and Pizzari, in press), supporting the view of Schärer et al. (2012) that sex-specific selection, arising ultimately from anisogamy, drives the evolution sexual dimorphism, rather than chance differences in male-female life history and mating traits.

\section{TRANSITIONS IN THE SEXUAL CASCADE}

The main transitions in the cascade in Figure 1 are outlined below as a series of discrete steps. Although, in general, the evolution of one step precedes and creates the selective pressure for the next, some synchrony in adaptation across adjacent steps seems likely. The cascade is driven initially by gamete competition and later (after the evolution of anisogamy) by sperm competition. As Darwin (1871) surmised, it is the rise of mobility and complex behavior that catalyzes the development of pre-ejaculatory (Darwinian) sexual selection; what Darwin missed was the long preceding history of sexual selection on gametes and gonads. As the importance of preejaculatory sexual selection increases, the optimal economic balance between pre- and postejaculatory expenditures shifts toward reduced testes mass and sperm production (i.e., toward lower precopulatory expenditure) (Parker et al. 2013).

The sexual cascade (Fig. 1) provides a logical imperative for pre-ejaculatory (Darwinian) sexual selection and for Darwin's (1871) and Bateman's (1948) claims about the link between the primary sexual differentiation (anisogamy) and the evolution of traditional sex roles, which has recently been challenged (in my view, unjustifiably) (see Parker and Birkhead 2013; Par- ker and Pizzari, in press). A more detailed account of some of the transitions is given in a companion paper to the present article (Parker and Pizzari, in press).

Transition A: Events Leading to an Ancestral Isogamous Eukaryote

A suite of transitions in evolution, ranging from the origin of life up to meiosis, recombination, gametic fusion (syngamy), mating types, and the haploid-diploid cycle in eukaryotes (see Maynard Smith and Szathmáry 1995), are here all grouped together (transition A, Fig. 1). Much of the evolution of these early stages remains shrouded in mystery, and interest in the selective advantage of sexuality over asexuality, which expanded in the 1970s (e.g., Williams 1975; Maynard Smith 1978), continues to preoccupy evolutionary biologists (Hartfield and Keightley 2012).

\section{Transition B: Evolution of Gamete Size Dimorphism (Two Sexes)}

The sexual cascade in eukaryotes begins with an isogamous unicell (Fig. 1). Transition B, from isogamy to anisogamy, is the key transition in the cascade because it marks the origin of two sexes (in my view, sexes should be defined in terms of gamete size produced and not confused with mating types) (Parker 2011; but see Hoekstra 2011 for an opposing opinion). Anisogamy is often associated with an increase in cellular complexity and is universal in Metazoa (see reviews of Lessells et al. 2009; Parker 2011).

Lessells et al. (2009) review the three main theories for the evolution of anisogamy from an ancestral isogamous unicellular eukaryote. Beginning with Cosmides and Tooby (1981), one theory proposes that anisogamy evolved in response to conflict between nuclear genes and genes in cytoplasmic elements such as mitochondria, chloroplasts, and intracellular parasites (reviewed by Hoekstra 2011). Lessells et al. (2009) conclude that cytoplasmic conflict models are unlikely to be an adequate sole explanation of anisogamy, although they may help to maintain it once evolved. 


\section{G.A. Parker}

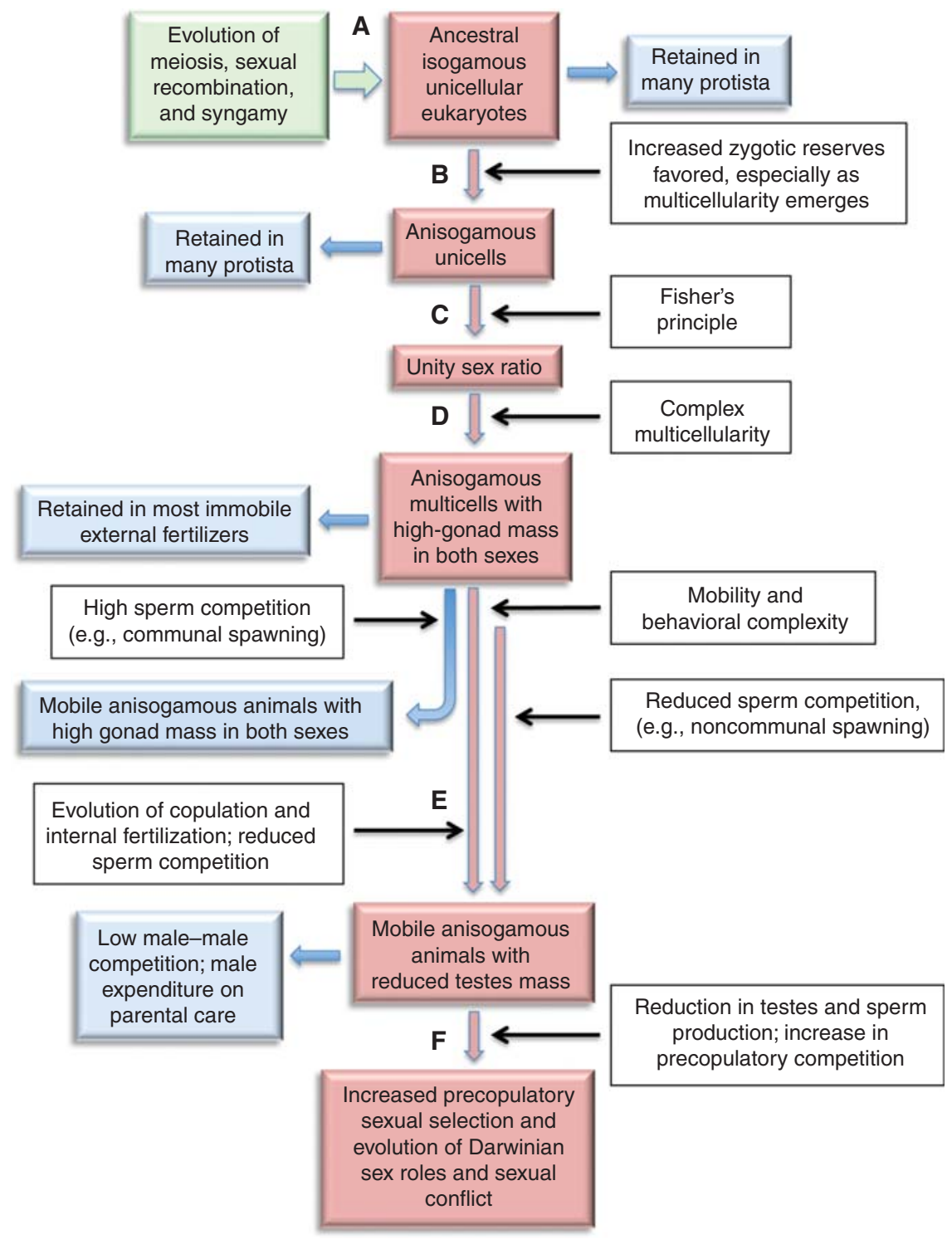

Figure 1. The sexual cascade (succession of evolutionary events leading to Darwinian sexual selection) (pink boxes and arrows) showing main transitions and selective forces (white boxes and black arrows) and alternative stable states (blue boxes and arrows). The transitions $(A-F)$ are explained in the text.

Two other theories appear more plausible because both are based only on a trade-off between size and number of gametes (inevitable in an ancestral unicell) and the fact that, over some range, the fitness (i.e., success or viability) of a zygote must increase with its size. The "gamete limitation" theory (e.g., Levitan 1996; beginning with a population-level proposal by Kal- mus 1932) relates to the fact that anisogamy could yield more surviving zygotes than isogamy. If some parents produce vast numbers of tiny gametes, this increases the probability of fertilization of the relatively low number of large gametes that survive well as zygotes. The "gamete competition" theory (Parker et al. 1972) relates to the fact that gamete competition can 
generate disruptive selection on an isogamous population leading to anisogamy (reviewed by Parker 2011). Again, large gametes survive well as zygotes, but intermediate and small gametes compete to gain most fusions with the large gametes. The ESS does not depend on whether the model assumes random fusion between gametes or begins with mating types. If selection favors increased complexity (e.g., toward multicellularity), then higher zygote size is favored, which increases the likelihood of anisogamy (Parker et al. 1972; Bulmer and Parker 2002).

An elegant recent analysis (Lehtonen and Kokko 2011) shows the relation between these two theories. Previously, both had been modeled as a large population of adults releasing gametes into an external medium (sea water). In Lehtonen and Kokko's model, (1) the number of adults in the local mating group could vary from two (i.e., no gamete competition) to infinity (maximum gamete competition), and (2) the rate of fusions of gametes could also vary, either by reducing gamete production rates or encounter rates or by increasing gamete mortality rates (see also Scudo 1967). They showed that anisogamy could evolve from isogamy through either gamete limitation or competition, depending on these two factors. When gametes can fuse fairly readily, even low levels of gamete competition (three or more adults per breeding group) generate anisogamy. However, gamete limitation (low gamete fusion rates) can also generate anisogamy, provided the number of adults per group remains low (i.e., low gamete competition). Which effect (gamete competition or limitation) has had the larger influence on the origin of anisogamy (and hence two sexes) depends on conditions experienced in ancestral isogamous unicells, but gamete competition appears the more robust selective force (Lessells et al. 2009) and one that leads naturally to sperm competition under external fertilization once anisogamy (and hence the two gamete-producing morphs, males and females) become established. Although this question may be difficult to resolve, gamete (sperm) competition certainly offers a plausible solution for the maintenance of anisogamy in most current populations (Parker 1982, 2011).
Early gamete competition models assumed simplistically that a gamete could survive successfully provided it was above a critical minimum size (Parker et al. 1972; Maynard Smith 1982); whether selection favors isogamy or anisogamy then depends critically on the importance of zygote size. More recent models (e.g., Bulmer and Parker 2002) include a function relating gamete survival to gamete size, as well as a function relating zygote fitness to zygote size. Which ESS (isogamy or anisogamy) is attained depends on how similar these two functions are. If similar, the ESS is isogamy, but if the zygote size-to-fitness function shifts away from the gamete size-to-fitness function, requiring much greater size to achieve the same fitness, the ESS is anisogamy (Bulmer and Parker 2002; Lehtonen and Kokko 2011). Exactly this sort of change toward larger zygotes is likely to have accompanied increasing organismal complexity during the evolution of multicellularity, and there is also empirical evidence that this is accompanied by a trend toward anisogamy (see review of Parker 2011). However, if selective pressures do not favor multicellularity, isogamy should remain fixed if the two functions remain rather similar, as seems likely in many unicells (although many show primitive forms of anisogamy).

Once sexual reproduction and syngamy have evolved, transition B (anisogamy) is thus likely to accompany the evolution of multicellularity and increased organismal complexity. It is associated with an immediate and primordial sexual conflict. If gametes can fuse readily, protofemales do better when their ova are fertilized by other ova rather than by parasitic, noncontributing sperm (Parker et al. 1972; Parker 1978c). Parker et al. (1972) proposed two reasons why sperm producers were likely to win: (1) Because the available mutations would be proportional to the number of gametes produced, sperm may have achieved a higher adaptation rate in coevolutionary battles. (2) If sperm-sperm fusions produced nonviable zygotes, sperm producers may have been under stronger selection to avoid sperm-sperm fusions and gain sperm-ovum fusions than ovum producers were to avoid sperm-ovum 


\section{G.A. Parker}

fusions. Parker (1978c, 2011) gives further reasons why an ovum producer carrying a mutation that prevented sperm-ovum fusions is likely to have been unsuccessful. However, if gametes cannot fuse readily and there is little gamete competition, anisogamy may evolve without conflict as a cooperative solution, as an individual selection extension of Kalmus' (1932) original proposal (Lehtonen and Kokko 2011).

\section{Transition C: Evolution of the Unity Sex Ratio}

The evolution of anisogamy may involve mutations that change gamete size by altering the number of cell divisions per unit of reproductive resource. Such a mutation would similarly affect all gametes produced by a given mutant individual, ultimately resulting in separate sexes (gonochorism) arising from two mating type lineages. This argument suggests that separate sexes would typically be ancestral for anisogamy arising in unicells. However, some primitive colonial forms such as Volvox include both hermaphrodite and gonochoristic species, so that it is not immediately clear whether the ancestral states would have been separate sexes or hermaphroditism for anisogamy arising in multicells. Because a hermaphrodite individual requires two types of gonad, economy suggests that specialism into separate sexes generally would be favored (Heath 1977), with hermaphroditism (or more complex hermaphroditic forms such as gynodioecy or androdioecy) being favored only under certain special conditions (Charnov et al. 1976).

Under gonochorism, Fisher's (1930) principle immediately operates to favor and maintain equal numbers of males and females. Essentially, the rarer sex has a fitness advantage that is lost only when equality is attained. The unity sex ratio (transition $\mathrm{C}$ ) is thus an immediate consequence for populations with two sexes (anisogamy) and arose in the original gamete competition simulations (Parker et al. 1972). Unless special circumstances apply (see Hamilton 1967; Charnov 1982; West 2009), equal production of the two sexes is maintained in a tight equilibrium. This selective constraint forms a vital part of sexual selection and conflict by ensuring that (1) in sessile or weakly mobile external fertilizers, numerous sperm must compete for rare ova, and (2) in internal fertilizers, if males have less "time out" than females, males must compete for matings with females.

\section{Transition D: Sperm Competition and Evolution of Complex Organisms with High Gonad Mass}

The evolution of multicellularity has been much discussed; it has evolved at least 25 times including several times in eukaryotes, but only once in animals (e.g., Grosberg and Strathmann 2007; Bonner 1998), and involves many conflicts (reviewed by Grosberg and Strathmann 2007). Complex multicellularity may be difficult to acquire, and its origin in plants and animals can be traced back to ancestral marine forms. Marine plants and immobile or weakly mobile invertebrates spend most of their reproductive effort on gametes (see Parker and Pizzari, in press); other expenditures include pheromones and various adaptations to enhance fertilization such as spawning synchrony. Because they have few other means of achieving reproductive success, massive gametic expenditure in both sexes results in a high proportion of the total body mass (the gonado-somatic index or GSI) being expended on gonads and gamete production (Parker and Pizzari, in press). Broadcast spawning, often synchronous, results in intensive sperm competition, which is predicted to maintain male gonad expenditure at very high levels (Parker and Pizzari 2010). It is interesting that male GSI in sessile or relatively immobile broadcast spawning marine animals can considerably exceed female GSI in some taxa (Parker and Pizzari, in press). Why this should be so is unclear; one might imagine that GSI, here, would be equal, with males showing reduced GSI when expenditure increases on traits associated with precopulatory sexual selection. In their vertebrate-dominated study, Hayward and Gillooley (2011) found similar GSI in both sexes, but much higher gamete production rates in females. 
At this ancestral stage of immobile (or relatively mobile) marine broadcast spawners, sexual selection is essentially postejaculatory and sexual conflict relates mainly to fertilization conflicts.

Transition E: Mobility/Behavioral Complexity and Evolution of Reduced Sperm Competition

Darwin (1871, p. 274) suggested that the reason male gametes are "brought to" female gametes, rather than the reverse, relates to the relative difficulty of transporting ova. Because of the risks of "at least a short transit through the waters of the sea," he plausibly suggested that as soon as organisms evolved some mobility, males would be favored if they "were to acquire the habit of approaching the female as closely as possible" to reduce risk to unprotected gametes. A transition from external to internal fertilization (usually by copulation) is associated with the colonization of the land (e.g., Dawkins and Carlisle 1976).

There are probably many reasons why mobility and behavioral complexity has arisen in animals, including more efficient feeding and escape from predators. However, once low motility was possible in certain animal taxa, sperm competition may have been a potent selective force favoring the evolution of increased mobility and "female-targeted" sperm release by males, leading ultimately to copulation with internal fertilization (Parker 1970, 1984), which all probably arose through combined selection to increase (1) fertilization gains in the intense sperm competition conditions characteristic of marine broadcast spawning and (2) the proportion of eggs fertilized, either through sperm limitation or high gamete mortality (e.g., after broadcast spawning). The dawn of mobility and behavioral complexity is, thus, the catalyst that permitted the rise of pre-ejaculatory sexual selection out of sexual selection by ejaculate competition. Mobile external fertilizers, such as fishes and many amphibians, typically show high degrees of female targeting, and whereas sperm competition remains intense, male GSI scores remain relatively high. Thus, mobility and behavioral complexity in external fertilizers appears inevitably to be linked with female targeting (e.g., amplexus behavior in anurans), although when sperm competition is intense, GSI often remains high, reducing only as sperm competition reduces (e.g., for fishes, see Stockley et al. 1997; for amphibians, see Byrne et al. 2002).

An immobile broadcast spawner has little option other than to maximize gamete production (in both sexes); males are thus committed to expend all their reproductive effort on sperm. The evolutionary steps by which increased mobility and behavioral complexity may, in some taxa, lead to reduced sperm competition and testis expenditure are interesting to contemplate. A possible sequence is as follows:

1. The weakly mobile ancestor has broadcast spawning with high GSI in both sexes. All reproductive effort is diverted to gametes, there is little secondary sexual dimorphism, and sperm limitation is relatively common.

2. Weak mobility permits and favors aggregation for synchronous spawning to increase fertilization probability for both sexes. The sex ratio in spawning aggregations would be close to unity because both sexes expend similarly on gametes.

3. Mutant males showing primitive female targeting are favored because they achieve sperm competition advantages (see below).

4. As female targeting spreads and becomes more advanced, then, because the sex ratio on spawning grounds is close to unity, sperm competition decreases as many of the spawnings occur in pairs.

5. Close association of the sexes at spawning decreases sperm limitation, reducing the advantage of spawning aggregation and synchrony to females.

6. Female targeting and pre-ejaculatory male competition advance further and costs to females of aggregation and male harassment favor female dispersion.

7. This further decreases sperm competition, reducing male GSI more and increasing 
G.A. Parker

male expenditure on pre-ejaculatory traits such as mate searching and other forms of male-male competition.

In support, many of the above steps appear to be "fossilized" in modern species. For example, following step 1, echinoderms are typically marine broadcast spawners with weak mobility, equal sex ratios, and GSIs; percentage fertilization is very variable, so that sometimes there is considerable sperm limitation (Levitan and Petersen 1995). Obvious secondary sexual dimorphism is very rare and restricted to special ecological conditions (Levitan 2005). As in step 2, many species show synchronous spawning in aggregations (e.g., Himmelman et al. 2008), in which fertility can then be high (Levitan 2010). Remarkably, steps 3-5 appear to be mimicked in the asteroid, Archaster typicus (Run et al. 1988). Here, especially, the males display increased mobility as the breeding season begins and show female targeting; they seek out and mount females and begin to release sperm immediately after the female spawns. Some $85 \%$ of spawnings occur in this way at peak breeding season. Fertilization efficiency is very high (95\% fertility occurred after pair spawnings). Male GSI is much less than that of females. The female $/$ male GSI ratio $=4.8$, which is aberrant and the highest found in the literature for 18 asteroid species (Table 3 in Run et al. 1988), otherwise ranges from 2.1 to 0.4 . Run et al. (1988), suggest that this may relate to the trade-off of gonad against the energetic demands of higher movement rates and female mounting in males. Himmelman et al. (2008) commonly witnessed similar "pseudocopulation" behavior during spawning in the ophiuroids Ophiopholis aculeata and Ophiura robusta, and (with much lower frequency, and in a less clearly defined manner) in the sea star Asterias vulgaris (which had the second most reduced male GSI in Table 1 in Run et al. 1988). The Antarctic sea star Neosmilaster georgianus, a brooding asteroid that probably reproduces continuously, may even have advanced to steps 6 and 7. Here the female targeting behavior involves one or several males mounting a reproductively active female for a period of minutes to hours before spawning
(Slattery and Bosch 1993), indicating that female harassment may be present.

Reduction in sperm competition is predicted theoretically to reduce male gonad expenditure (see models reviewed in Parker and Pizzari 2010). There is some empirical evidence for this in external fertilizers and abundant evidence across many internally fertilizing taxa (reviewed in Simmons and Fitzpatrick 2012), so that relative testes size is now commonly used as an index of the level of sperm competition. However, the key to reduced sperm competition in the above sequence of steps relates to female targeting coupled with spatial dispersion of females. Ejaculate and testis economy arise because expenditure devoted to finding and targeting sperm release toward females can yield higher fertilization gains than sheer numerical sperm productivity alone. But paradoxically, as pre-ejaculatory expenditure increases at the expense of postejaculatory expenditure, the OSR is likely to become increasingly malebiased, which can allow some restoration of sperm competition level, depending on female propensity for multiple mating.

Male GSI in broadcast spawners is typically much higher than in taxa with copulation and internal fertilization (Table 1 in Parker and Pizzari, in press). But is sperm competition generally reduced by internal fertilization? One argument might be that, in internally fertilizing species, sperm is often provisioned within the female sperm stores, giving greater longevity and more opportunity for sperm competition than external fertilizers, where the typical sperm life is short. However, many external fertilizers have high spawning synchrony, sometimes in mass aggregations, whereas internal fertilizers are often more dispersed. Furthermore, internal fertilization gives females the opportunity to resist copulations, and varying degrees of female unreceptivity (often after an initial mating) are common in many species, probably because the costs of polyandry to females are often significant, whereas the benefits are often (but not always) marginal. Thus, if females move to areas where males occur in high density, they often mate with one male and then leave. Very low sperm competition risk tends to occur in 
internal fertilizers that typically mate just once per reproductive cycle. When there is multiple mating, male GSI in internal fertilizers tends to be rather comparable with that of aggregating mobile external fertilizers, but less than (and, often, much less than) that of immobile or weakly mobile broadcast spawners (Table 1 in Parker and Pizzari, in press). Thus, in general, sperm competition appears to be lower under internal fertilization, although there is much overlap depending on the mating system.

Is male GSI high in broadcast spawners because of sperm limitation or competition? Note that sperm limitation per se does not affect the level of sperm competition, which increases with the number of non-self sperm in competition with self-sperm; even if only a small proportion of eggs are fertilized, with broadcast spawning, a given ejaculate may compete with many other ejaculates for fertilizations. Whether species are subject to sperm limitation or competition, then all else being equal, it pays for males to increase sperm numbers. Only when males face neither sperm competition nor limitation can it pay to decrease sperm numbers. Immobile species have little option other than to spend their reproductive effort on gametes, but mobility can generate an alternative, more profitable expenditure on pre-ejaculatory traits associated with female targeting.

Transition F: The Rise of Pre-Ejaculatory Sexual Selection, Sex Roles, and Sexual Conflict

The above key transition E, that is, from broadcast spawning to searching for and targeting sperm release toward females, leading ultimately to the ubiquitous occurrence of copulation in most terrestrial animals, thus marks the rise of pre-ejaculatory (Darwinian) sexual selection. As copulation and internal fertilization evolve, relative potential gains through precopulatory sexual competition can become more favorable than sperm expenditure, especially if sperm competition reduces. Thus, precopulatory expenditure rises at the expense of testis and ejaculate expenditure. In contrast, female gametic expenditure typically remains high. Ultimately, it is the transition to extensive male precopulatory expenditure that results in a high differentiation of sex roles as Darwin envisaged (i.e., the DBP) and high levels of sexual conflict. Sperm economy results in a different balance between time spent on gametic investment for males and females (Williams 1966), which translates into the sexual asymmetry in parental investment (Trivers 1972), OSR (Emlen and Oring 1977), and PRR (Clutton-Brock and Vincent 1991), all of which can be related to times in or out of the mating pool (Clutton-Brock and Parker 1992), and generate divergence in sex roles envisaged by Darwin (see Parker and Birkhead 2013).

It is important to separate the evolution of parental care, which is a labile, secondary phenomenon that is actually relatively infrequent, viewed across the animal kingdom as a whole, from the primary, prezygotic parental investment in gametes. It commonly involves sexual conflict and sometimes also cooperation (see review of Székely 2014). Gametic parental investment occurs symmetrically for parents in isogamy, but for sound theoretical reasons (Parker 1982; Lehtonen and Kokko 2011), it is confined to female investment as ovum provisioning in species with advanced anisogamy (the selective forces underlying sperm and ovum size are reviewed in Parker 2011). In contrast, patterns of parental care of zygotes are highly diverse and have evolved many times independently (Clutton-Brock 1991), but maternal care is much more common than paternal care. The selective mechanisms underlying parental care patterns are less clearly understood than those underlying gametic investment, and exactly what shapes the form of parental care and how it links to anisogamy (which, empirically, it appears to) remains controversial. The ecological lability of parental care allows, not infrequently in certain taxa, deviations from traditional DBP sex roles through the evolution of paternal care. Although Trivers (1972) linked the predominance of female care directly to anisogamy, this has been disputed many times since. Dawkins and Carlisle (1976) pointed out that previous investment does not a priori affect future investment, and argued plausibly that other biological circumstances, such as external versus internal 


\section{G.A. Parker}

fertilization, could affect the pattern of care. For instance, males of internally fertilizing species are typically not present when their young are released, so male care is, here, harder to evolve than in externally fertilizing species (see also Maynard Smith 1977). Since then, the literature has expanded extensively (reviewed by Klug et al. 2013a), and a direct effect of anisogamy in weighting parental care toward females has been increasingly questioned (see, e.g., Queller 1997; Kokko and Jennions 2008; Klug et al. 2013a). Most recently, Klug et al. (2013a,b) have examined life history conditions favoring transitions from existing states. When the ancestral state is no care, although females initially invest more into each zygote than males, paternal, maternal, and biparental care are equally likely to evolve if males and females are otherwise similar (Klug et al. 2013a). However, once some form of parental care has evolved, then as male and female gametic investment becomes more disparate, with females investing heavily in eggs in a way that decreases their future reproductive success, transitions to increased maternal care (paternal $\rightarrow$ maternal, paternal $\rightarrow$ biparental, biparental $\rightarrow$ maternal) are more likely to be favored (Klug et al. 2013b) as the stable state. This link with anisogamy may well help to explain the predominance of female care in nature.

When ecological or life history conditions do reverse sex roles, selection cannot produce a drive back to isogamy by allowing males to increase sperm size to assist in provisioning zygotes, but males can instead evolve paternal investment. An obvious reason for this is that although paternal care can be focused on zygotes, extra investment per sperm for zygote provisioning would largely be wasted on the vast numbers of sperm that do not fertilize ova (Parker 1982, 2011; Lehtonen and Kokko 2011). Once attained and specialized, the twosex state becomes highly stable.

\section{THE EVOLUTION OF MOBILITY AND FEMALE-TARGETED SPERM RELEASE}

The key event leading to the rise of pre-ejaculatory (Darwinian) sexual selection is the evolu- tion of advanced mobility, transition E (Fig. 1). Although the initial impetus for mobility could have been related to pressures such as improved food gathering and predator avoidance, these are likely to have been greatly enhanced by intrasexual selection on males to release gametes closer to females, and females to move closer to males to reduce sperm limitation (see above). Because of the importance, as Darwin (1871) recognized, of the evolution of mobility and behavioral complexity, I have investigated a simple prospective model to explain (1) the conditions important for transition $\mathrm{E}$ through sexual selection alone, and (2) why some invertebrate groups remain fixed as sessile or weakly mobile external spawners with vast expenditure on testes and sperm production.

The model (for details, see Box 1) considers a hypothetical marine invertebrate with weak mobility in which males and females gather in large groups to undergo broadcast spawning (Fig. 2). It calculates the initial "boost" to increased mobility given by sexual selection on males to reduce sperm competition by examining the fitness of a rare mutant male that moves to "target" his sperm release toward spawning females. A biologically realistic interpretation of the model could be that both sexes use their weak mobility to aggregate for spawning-they move closer together and then become stationary, awaiting the start of gamete release. The mutation we consider causes males to enhance this movement further; instead of remaining stationary, the mutant moves toward spawning females while releasing sperm. Although the model considers only the first step in female targeting, it is easy to see how continued drive for such a process could lead to females conserving energy by reducing their aggregation behavior, because as female targeting by males becomes more advanced, sperm limitation reduces (see above). This, in turn, increases the benefits of mate searching by males, driving ultimately toward highly mobile mate searching and highly female-targeted sperm release, and often, ultimately, copulation and internal fertilization. It is not inconceivable that autosomal mutations for enhanced mobility that were initially favored in males through this form of sexual selection were 
The Sexual Cascade

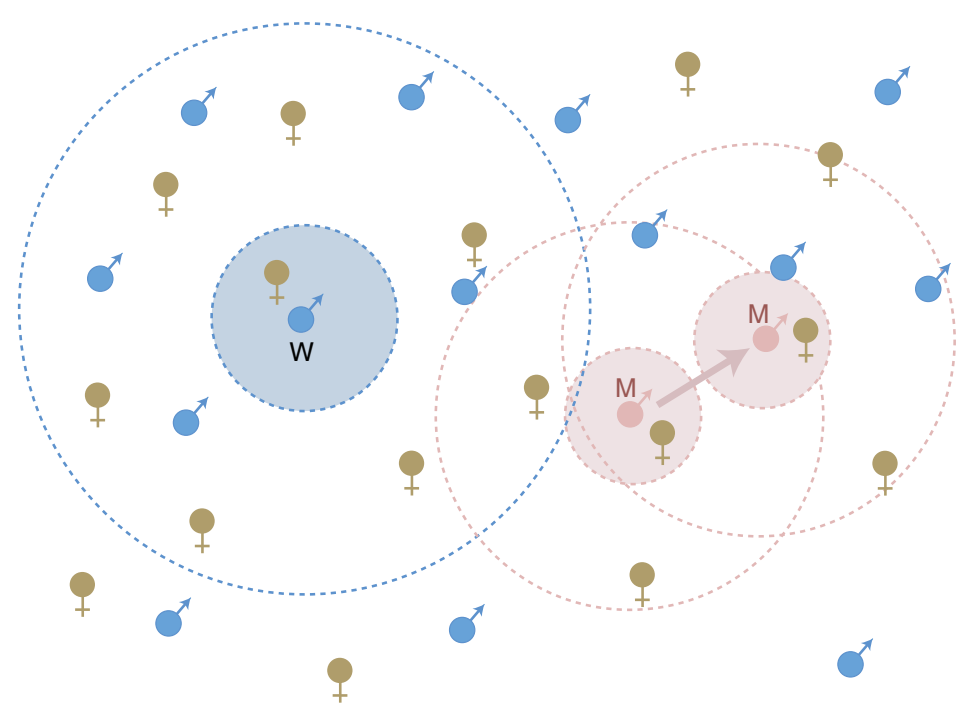

Figure 2. Schematic representation of the model for the evolution of female-targeted sperm release. Wild-type males (blue male symbols) and females (brown female symbols) have low mobility and broadcast gametes. Males releasing sperm have a fertilization zone, $\beta$, depicted by the outer broken circles: In this zone, they compete with males with overlapping zones. They gain higher fertilization success with a proportion, $\alpha$, of females ("nearby" females, represented as those within the blue shaded area around the focal wild-type male), but lower fertilization success with a proportion $(1-\alpha)$ of females ("distant" females, represented as the white area between the concentric broken blue circles). A mutant male ( pink male symbol) that moves to target females pays for this by having a reduced total sperm release, which changes zone $\beta$, but increases the proportion of nearby females.

also of benefit to both sexes for more efficient food foraging or predator avoidance.

To return to the model: A male's total sperm production is assumed to be proportional to his expenditure $G$ on gonad, and his sperm can fertilize eggs shed by spawning females in a zone $\beta$ around him (Fig. 2). Within this zone, he has higher fertilization success with a proportion $\alpha$ of females closest to him, and lower success with the proportion $(1-\alpha)$ of females in $\beta$ that are further away. The male can also expend $M$ on limited movement during the spawning period. This trades off with gonad expenditure within a fixed reproductive budget, $R$ (thus, $R=M+G$ ). Suppose, now, that a mutant male arises that increases $M$ so as to target females, that is, by moving toward spawning females, its proportion $\alpha$ of "nearby" fertilizations increases. The model, which is prospective only, seeks the ESS expenditure $\left(M^{*}\right)$ on this primitive form of mate searching.

Despite the fact that the mutant's fertilization zone $\beta$ will deviate from the rest of the population because of the change in $M$ and $G$, the ESS (at least in this simple model) does not depend on $\beta$. Varying $\beta$ changes the number of females, but similarly changes the number of competing males in the fertilization zone such that the two effects cancel each other out. Thus, the ESS expenditure, $M^{*}$ (see Box 1, Equation 3) depends only on (1) the total resources for reproduction, $R,(2) \phi$, an index of the fertilization skew toward nearby females $(\phi=1$ if there is no fertilization difference between nearby and distant females, and rises above 1.0 as fertilization skew toward nearby females increases), and (3) on $\alpha(M)$, which defines how mobility spent on female targeting increases the proportion of nearby females in the fertilization zone $\beta$.

Some implications of this ESS were investigated using exponentially diminishing returns, that is, $\alpha(M)=1-\exp (-\mu M)$, in which increasing $\mu$ increases the rate at which $\alpha(M)$ approaches its asymptotic value of 1.0 (Fig. $3 \mathrm{~A})$. Figure 3B shows how the ESS, $M^{*}$, changes with the relative benefit of nearby females 


\section{G.A. Parker}

\section{BOX 1. THE EARLY EVOLUTION OF FEMALE-TARGETED SPERM RELEASE}

The following model examines the conditions that would favor the early evolution of female-targeted sperm release in an ancestral broadcast spawner; it makes a number of simplifying assumptions in the interest of mathematical tractability and is heuristic only. A schematic representation is given in Figure 2.

Imagine a population of relatively immobile animals that shed gametes into the sea for fertilization. Each female releases $E$ ova during spawning, and each male sheds $s$ sperm. Adults have an amount of resource, $R$, to spend on reproductive effort, most of which ( $G$ units) is spent on gonad (and, hence, gametes) and rather little ( $M$ units) on (limited) mobility. Thus, $R=M+G$, and for males, the number of sperm produced, $s$, increases linearly with the gonad investment as $G=g s$. In this population, each wild-type (nonmutant) male releases $\hat{s}$ sperm and has allocations $\hat{M}$, $\hat{G}$. When such a male releases sperm, he is closer to a proportion $\alpha(\hat{M})=\hat{\alpha}$ of "nearby" females, and hence (per female) fertilizes relatively more of their ova, and relatively less (per female) with the proportion $(1-\hat{\alpha})$ of "distant" females (Fig. 2). Suppose that there is a local spawning population density of $m$ males and $f$ females. Males gain fertilizations in a zone $\beta$ around them and experience sperm competition depending on the number of other males with overlapping zones. The zone around each wild-type male increases with his sperm expenditure, $\hat{G}$. We use the function $\beta(G, M)$ to define the limits of the fertilization zone. For wild-type males, $\beta(\hat{G}, \hat{M})=\hat{\beta}$, so that the zone overlaps with $\hat{\beta} f$ spawning females and $\hat{\beta} m$ spawning males (Fig. 2).

We calculate fertilization gains using a loaded raffle model (Parker and Pizzari 2010). The sperm competition advantage in fertilization with nearby females is modeled by giving a focal male's sperm a higher "competitive weight" with nearby females and a lower competitive weight with distant females by applying different loading factors to sperm in nearby and distant conditions (respectively, $h_{n}$ and $h_{d}$, where $\left.h_{n}>h_{d}\right)$. Thus, a wild-type focal male competing with $(\hat{\beta} m-1)$ similar males gains $\left.w_{n}(\hat{s}, \hat{\alpha})=\hat{\beta} f E g \hat{s} \hat{\alpha} h_{n} /\left\{g \hat{s}\left[\hat{\alpha} h_{n}+(1-\hat{\alpha})\right] h_{d}(\hat{\beta} m-1)\right]\right\}$ fertilizations with nearby females, and $\left.\left.w_{d}(\hat{s}, \hat{\alpha})=\hat{\beta} f \operatorname{Eg} \hat{s}(1-\hat{\alpha})\right] h_{d} /\left\{g \hat{s}\left[\hat{\alpha} h_{n}+(1-\hat{\alpha})\right] h_{d}(\hat{\beta} m-1)\right]\right\}$ with distant females, so that his total fertilizations are $w(\hat{s}, \hat{\alpha})=w_{n}(\hat{s}, \hat{\alpha})+w_{d}(\hat{s}, \hat{\alpha})=f E / m=E$ if the sex ratio is unity $(f=m)$.

Now, consider the fertilization success of a mutant focal male with increased mobility $(M>\hat{M})$ that releases $s<\hat{s}$ sperm (because $G<\hat{G}$ ). He experiences two effects as a result of his increased mobility (see Fig. 2): (1) He targets his sperm release toward nearby spawning females by moving toward them and releasing sperm, thus increasing his proportion of nearby spawning females to $\alpha=\alpha(M)>\hat{\alpha}$, that is, a primitive form of mate searching, and (2) he alters his fertilization zone $\beta$, so that the population of individuals (of both) sexes overlapping with his zone changes to $\beta=\beta(G, M) \neq \hat{\beta}$ compared with wild-type males.

The nature of the change in $\beta$ is harder to predict than that in $\alpha$. If a male increases his mobility from $\hat{M}$ to $M$, he reduces the number of sperm he releases because of the trade-off, $G=R-M$, so that $s<\hat{s}$. This suggests that $\beta<\hat{\beta}$ because the mutant has a lower total sperm release, but because the mutant moves more through the spawning population, this assumption could be questioned. However, if we assume that the mutant experiences the same proportionate change in the number of male competitors and spawning females, he competes with $(\beta m-1)$ males, each releasing $\hat{s}$ sperm, for fertilizations of $\beta f E$ eggs, and we shall see later that the form of $\beta(G, M)$ does not influence the ESS.

The mutant's total fertilizations are

$$
w(s, \hat{s})=\frac{\beta f E g s\left(\alpha h_{n}+[1-\alpha] h_{d}\right)}{\left\{s g\left[\alpha h_{n}+(1-\alpha) h_{d}\right]+\hat{s} g\left[\hat{\alpha} h_{n}+(1-\hat{\alpha})\right] h_{d}(\beta m-1)\right\}} .
$$

Dividing both numerator and denominator by $h_{d}$ and simplifying, we can write this as

$$
w(s, \hat{s})=\frac{\beta f E s g[\alpha(\phi-1)+1]}{\{s g[\alpha(\phi-1)+1]+\hat{s} g[\hat{\alpha}(\phi-1)+1](\beta m-1)\}},
$$

where $\phi=h_{n} / h_{d}>1$, an index of the fertilization skew toward nearby females. Note that when the 
focal mutant plays the population strategy, that is, $s=\hat{s}$ so that $\alpha=\hat{\alpha}$, we see that again $w(\hat{s}, \hat{s})=f E / m$.

To find the ESS value for $s$, that is, $s^{*}$, we set

$$
\left.\frac{d w}{d s}\right|_{s=\hat{s}=s^{*}}=0, \quad \text { subject to }\left.\frac{d^{2} w}{d s^{2}}\right|_{s=\hat{s}=s^{*}}<0,
$$

for a maximum, remembering that both $\alpha$ and $\beta$ are functions of $s$. This differentiation of Equation 1 involves terms $\beta$ and $d \beta / d s$, but we eventually obtain

$$
-s^{*} \frac{d \alpha\left(M^{*}\right)}{d s}=\alpha\left(M^{*}\right)+\frac{1}{\phi-1},
$$

where the asterisks denote ESS values. Note that the $\beta$ terms disappear. Effectively, decreasing $\beta$ changes the number of females in the fertilization zone, but also similarly changes the number of males in competition, and the two effects cancel out each other. A more advanced model may examine this result in more detail, but we believe it to be a reasonable first approximation for this heuristic model.

Allocations $M$ and $G$ trade off within the male's reproductive budget, $R$. For simplicity, we have assumed that the amount of sperm released, $s$, is a linear function of the total mass of the gonad, that is, $G(s)=$ gs and $M(s)=R-g s$. Thus,

$$
d \alpha\left(M^{*}\right) / d s=-g \cdot d \alpha\left(M^{*}\right) / d M
$$

Equation 2 then gives

$$
\left(R-M^{*}\right) \frac{d \alpha\left(M^{*}\right)}{d M}=\alpha\left(M^{*}\right)+\frac{1}{\phi-1} .
$$

We now have a solution solely in terms of (i) the function $\alpha(M)$, which defines how female targeting increases the proportion of "nearby" females, (ii) $\phi$, which defines the fertilization skew toward nearby females, and (iii) $R$, the male's reproductive budget.

A plausible form for $\alpha(M)$ in this ancestral state would be an increasing function with diminishing returns. Setting $\alpha(M)=1-\exp (-\mu M)$, $\mu$ defines the rate of approach to the asymptotic value of $\alpha(M)=1.0$ (Fig. 3A). We cannot obtain an explicit solution for $\mathcal{M}^{*}$, but Equation 3 gives

$$
\exp \left(-\mu M^{*}\right)\left[1+\mu\left(R-M^{*}\right)\right]=\phi /(\phi-1)
$$

which can be used to iterate solutions for $M^{*}$ (see Fig. 3B). As $(\phi-1)$ increases, the ESS mobility level increases toward an asymptote determined by $\mu$. Note that highest ESS values for mobility and female targeting $\left(M^{*}\right)$ are obtained when $\mu$ is low and $(\phi-1)$ high, although the range over which at least some degree of female targeting can be favored increases with $\mu$.

We can ask what conditions permit the initial evolution of female targeting, that is, for a relatively immobile broadcast spawner to begin to move toward spawning females (the condition for $M^{*}>0$ ). This depends only on the starting gradient of $\alpha(M)$, that is, on $d \alpha(0) / d M$. Applying either the exponential function above or the linear form $\alpha(M)=\mu M$ to Equation 3, we find that the condition for female targeting to begin to evolve is simply that

$$
\mu(\phi-1)>R^{-1}
$$

The product of the marginal gain from increasing nearby females $(\mu)$ and relative fertilization skew $(\phi-1)$, must exceed the reciprocal of the male's resource available for reproduction; if this can occur, the transition from sheer numerical sperm productivity toward sperm economy and female targeting begins. 
G.A. Parker
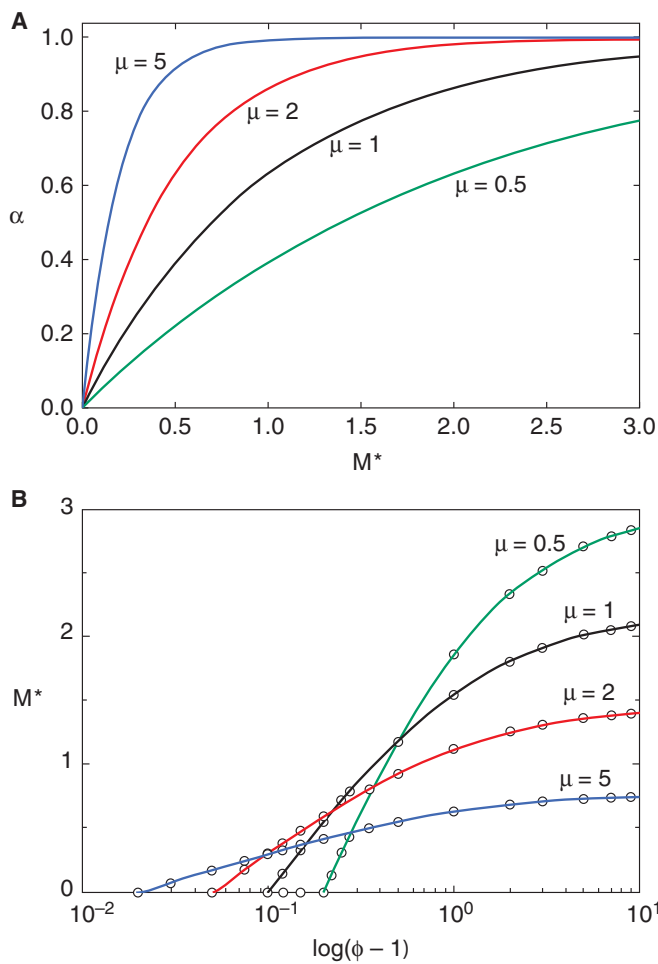

Figure 3. (A) Relation between $\alpha$, the proportion of "nearby" females and a male's expenditure on monility and female targeting, $M$. (B) Relation between the ESS mobility, $M^{*}$, and the log index of fertilization skew toward nearby females, $\log (\phi-1)$, at different values for $\mu$, which defines the rate at which $\alpha(M)$ increases to its asymptote.

$[\log (\phi-1)]$. If the relative fertilization benefit of nearby females is small $(\phi \rightarrow 1)$, female targeting will not evolve and the ESS is to remain as an immobile broadcast spawner, and if $\mu$ is also low, even moderate benefit of nearby females will not permit mobility to evolve. However, high benefits of nearby females $(\phi \gg 1)$ result in significant mobility, generating very high $M^{*}$ when $\mu$ is low. When $\mu$ is low, $\alpha(M)$ is slow to approach its asymptote (Fig. 3A), so that the marginal benefits of continued mobility investment are high. When $\mu$ is high, large amounts of female targeting can be achieved with low $M$, so high gonad investment can be maintained to aid in sperm competition.

So, what biological conditions allow immobility and high gonad mass to be maintained in broadcast spawners? Many multicellular plants are sessile and fixed to the substrate, and hence cannot move, as is the case for many marine invertebrates. Marine invertebrates with weak or moderate mobility often have highly synchronous spawning, which may reduce the benefits of female targeting because gametes are shed very quickly and synchronously. Similarly, if individuals are much dispersed, costs of moving to and targeting spawning females may be high. Empirical studies of the relevant parameters in weakly mobile marine invertebrates would repay detailed investigation.

This simplistic model thus shows the sort of conditions under which female-targeted sperm release may have begun to evolve, and also why many taxa retain broadcast spawning. It predicts the initial rise of mobility for female targeting if $\mu(\phi-1)>R^{-1}$ (Box 1, Equation 5). The three conditions favoring this crucial transition for preejaculatory sexual selection are (1) high initial increases in the proportion of nearby females by diverting resources from gonad to mobility (high $\mu$ ), (2) high relative fertilization benefits with nearby females (high $\phi$ ), and (3) high resources for reproduction (high $R$ ). The first two requirements would seem more likely to be satisfied as behavioral complexity and high mobility advance. A possibility is that an initial drive in certain taxa to increase mobility for food foraging purposes raised resources (increased $R$ ) and made female targeting more effective (raised $\mu$ ), causing a sudden acceleration in female targeting. Selection would then act to increase its effectiveness, resulting in many taxa in a drive toward mate searching by males, copulation and internal fertilization, and greatly reduced sperm competition. This would be accompanied by greater potential for expenditure on more intense premating competition $(M)$ with consequently reduced gonad expenditure $(G)$ (Parker and Pizzari 2010; Parker et al. 2013). Effectively, this transition signifies the rise of pre-ejaculatory sexual selection, the form of selection discussed by Darwin.

\section{SEXUAL CONFLICT IN THE SEXUAL CASCADE}

Although pre-ejaculatory (Darwinian) sexual selection appears only at late stages in the cas- 
cade (Fig. 1), sexual selection acting on gametes begins after the evolution of syngamy and is likely to have been fundamental in generating two sexes (anisogamy). At this initial stage, sexual conflict concerns the fact that protofemales share the high investment they put into protoova with protomales, whose gametes (protosperm) contribute little, and as anisogamy advances, nothing. This is essentially the twofold cost of sex (Maynard Smith 1978). The reasons why males were likely to win this primordial sexual conflict, and why anisogamy is maintained, are reviewed by Parker (2011). As complex multicellularity advanced, potent sexual selection persists as sperm/pollen competition and cryptic female choice in the two major kingdoms, with sperm/pollen competition maintaining high relative male gonad investment unless (as in many animal taxa) mobility evolves. In sessile animals, sexual conflict will involve fertilization conflicts relating to, for example, selection of favorable sperm, genetic compatibility, and prevention of polyspermy. It will also concern parental care, which has evolved mainly (but not exclusively) as maternal care in several sessile or weakly mobile invertebrates, but sometimes also as paternal care in mobile external fertilizers such as several amphibians and many fish.

With the evolution in many animal taxa of advanced mobility and female targeting, often involving copulation, testes reduction accompanies the rise of pre-ejaculatory (Darwinian) sexual selection and evolution of sex roles. Testes reduction and the typical absence of male parental care result in male time in the mating pool greatly exceeding female time and relates to high intensity of sexual selection on males (e.g., Clutton-Brock and Parker 1992; Kokko et al. 2012; Parker and Birkhead 2013). Precopulatory sexual selection and the highly differentiated sex roles that often result from it, now generate a second dimension for sexual conflict: mating conflict. Conflicts over mating decisions will most typically be of the DBP type with males selected to persist and females to resist and may accompany mating decisions over inbreeding, mate quality, and crosses between ecotypes, and, hence, the probability of speciation (Parker
1979, 2006b; Parker and Partridge 1998). However, conflict will also arise from adaptations to sperm competition and may, too, be extensive (reviewed by Stockley 1997; Edward et al. 2014).

Recent critiques that DBP sex roles are unrelated to the primary sexual differentiation (anisogamy) are therefore unfounded (see also Schärer et al. 2012); sex roles flow logically from anisogamy as a consequence of the sexual cascade and, as such, present no fundamental inconsistency (Parker and Birkhead 2013; Parker and Pizzari, in press).

\section{ACKNOWLEDGMENTS}

I am grateful to Bill Rice and Sergey Gavrilets for the invitation to write this review, which has allowed me to elaborate on my ideas surrounding the sexual cascade that I developed for a monograph in the 1970s, but failed to complete, and ultimately abandoned. I am greatly indebted to Hanna Kokko, Lucas Schärer, and an anonymous reviewer for some very helpful suggestions that have much improved the manuscript. I also thank Tom Pizzari for several earlier discussions on this topic.

\section{REFERENCES}

${ }^{*}$ Reference is also in this collection.

Andersson MB. 1994. Sexual selection. Princeton University Press, Princeton, NJ.

Andrés JA, Morrow EH. 2003, The origin of interlocus conflict: Is sex linkage important? J Evol Biol 16: 219-223.

Arnqvist G. 1989. Multiple mating in a water strider: Mutual benefits or intersexual conflict? Anim Behav 38: 749-756.

Arnqvist G, Rowe L. 1995. Sexual conflict and arms races between the sexes: A morphological adaptation for control of mating in a female insect. Proc $R$ Soc Lond B 261: $123-127$.

Arnqvist G, Rowe L. 2005. Sexual conflict. Princeton University Press, Princeton, NJ.

Bateman AJ. 1948. Intra-sexual selection in Drosophila. Heredity 2: $349-368$.

Birkhead TR. 2000. Promiscuity: An evolutionary history of sperm competition. Harvard University Press, Cambridge, MA.

Birkhead TR. 2010. How stupid not to have thought of that: Post-copulatory sexual selection. J Zool 281: 78-93.

Birkhead TR, Møller AP. 1992. Sperm competition in birds: Evolutionary causes and consequences. Academic, London. 


\section{G.A. Parker}

Birkhead TR, Møller AP. 1998. Sperm competition and sexual selection. Academic, London.

Bonner JT. 1998. The origins of multicellularity. Integr Biol 1: $27-36$.

Bulmer MG, Parker GA. 2002. The evolution of anisogamy: A game-theoretic approach. Proc $R$ Soc Lond B 269: 2381-2388.

Byrne PG, Roberts JD, Simmons LW. 2002. Sperm competition selects for increased testes mass in Australian frogs. J Evol Biol 15: 347-355.

Chapman T, Arnqvist G, Bangham J, Rowe L. 2003. Sexual conflict. Trends Ecol Evol 18: 41-47.

Charnov EL. 1982. The theory of sex allocation. Princeton University Press, Princeton, NJ.

Charnov EL, Maynard Smith J, Bull JJ. 1976. Why be an hermaphrodite? Nature 263: 125-126.

Clutton-Brock TH. 1991. The evolution of parental care. Princeton University Press, Princeton, NJ.

Clutton-Brock TH, Vincent ACJ. 1991. Sexual selection and the potential reproductive rates of males and females. Nature 351: 58-60.

Clutton-Brock TH, Parker GA. 1992. Potential reproductive rates and the operation of sexual selection. Q Rev Biol 67: 437-456.

Cosmides LM, Tooby J. 1981. Cytoplasmic inheritance and intragenomic conflict. J Theor Biol 202: 74-101.

Darwin C. 1871. The descent of man selection in relation to sex. John Murray, London.

Davies NB. 1992. Dunnock behaviour and social evolution. Oxford University Press, Oxford.

Dawkins R. 1976. The selfish gene. Oxford University Press, Oxford.

Dawkins R, Carlisle TR. 1976. Parental investment, mate desertion and a fallacy. Nature 262: 131-133.

Dawkins R, Krebs JR. 1979. Arms races between and within species. Proc R Soc Lond B 205: 489-511.

Dewsbury DA. 2005. The Darwin-Bateman paradigm in historical context. Integr Comp Biol 45: 831-837.

Eberhard WG. 1985. Sexual selection and animal genitalia. Harvard University Press, Cambridge, MA.

Eberhard WG. 1996. Female control: Sexual selection by cryptic female choice. Princeton University Press, Princeton, NJ.

Eberhard WG. 2005. Evolutionary conflicts of interests: Are female sexual decisions different? Am Nat 165: S19-S25.

Eberhard WG. 2009. Postcopulatory sexual selection: Darwin's omission and its consequences. Proc Natl Acad Sci 106: $10025-10032$.

* Edward DA, Stockley P, Hosken DJ. 2014. Sexual conflict and sperm competition. Cold Spring Harb Perspect Biol doi: 10.1101/cshperspect.a017707.

Emlen ST, Oring LW. 1977. Ecology, sexual selection, and the evolution of mating systems. Science 197: 215-223.

Fisher RA. 1930. The genetical theory of natural selection. Oxford University Press, Oxford.

Fisher RA. 1931. The evolution of dominance. Biol Rev 6: 345-368.

Gavrilets S. 2000 Rapid evolution of reproductive barriers driven by sexual conflict. Nature 403: 886-889.
Grafen A. 1990. Biological signals as handicaps. J Theor Biol 144: 517-546.

Grosberg RK, Strathmann RR. 2007. The evolution of multicellularity: A major minor transition? Ann Rev Ecol Evol Syst 38: 621-654.

Hamilton WD. 1967. Extraordinary sex ratios. Science 156: 477-488.

Hamilton WD, Zuk M. 1982. Heritable true fitness and bright birds: A role for parasites? Science 213: 384-387.

Hartfield M, Keightley PD. 2012. Current hypotheses for the evolution of sex and recombination. Integr Zool 7: 192 209.

Hayward A, Gillooley JF. 2011. The cost of sex: Quantifying energetic investment in gamete production by males and females. PLoS ONE 6: e16557.

Heath DJ. 1977. Simultaneous hermaphroditism: Cost and benefit. J Theor Biol 64: 363-373.

Himmelman JH, Dumont CP, Gaymer CF, Vallières C, Drolet D. 2008. Spawning synchrony and aggregative behaviour of cold-water echinoderms during multi-species mass spawnings. Mar Ecol Prog Ser 361: 161-168.

Hoekstra RF. 2011. Nucleo-cytoplasmic conflict and the evolution of gamete dimorphism. In The evolution of anisogamy: A fundamental phenomenon underlying sexual selection (ed. Togashi T, Cox PA), pp. 111-130. Cambridge University Press, Cambridge.

Holland B, Rice WR. 1998. Chase-away sexual selection: Antagonistic seduction versus resistance. Evolution 52: $1-7$.

Holland B, Rice WR. 1999. Experimental removal of sexual selection reverses intersexual antagonistic coevolution and removes a reproductive load. Proc Natl Acad Sci 96: 5083-5088.

Hosken D, Snook R. 2005. How important is sexual conflict? Am Nat 165: S1-S4.

* Hurst GDD, Frost CL. 2014. Reproductive parasitism: Maternally inherited symbionts in a biparental world. Cold Spring Harb Perspect Biol doi: 10.1101/cshper spect.a017699.

Huxley J. 1938a. Darwin's theory of sexual selection and the data subsumed by it, in the light of recent research. Am Nat 72: 416-433.

Huxley JS. 1938b. The present standing of the theory of sexual selection. In Evolution: Essays on aspects of evolutionary biology (ed. de Beer GR), pp. 11-42. Oxford University Press, Oxford.

Jacobs ME. 1955. Studies on territorialism and sexual selection in dragonflies. Ecology 36: 566-86.

Jennions MD, Kokko H. 2010. Sexual selection. In Evolutionary behavioral ecology (ed. Westneat DF, Fox CW), pp. 343-364. Oxford University Press, Oxford.

Kalmus H. 1932. On the adaptive value of phenotypic (morphological) anisogamy and the evolution of the first sex differences. Biol Zentral 52: 716-726.

Kirkpatrick M. 1982. Sexual selection and the evolution of female choice. Evolution 36: 1-12.

Kokko H, Jennions MD. 2008. Parental investment, sexual selection, and sex ratios. J Evol Biol 21: 919-948. 
* Kokko H, Jennions MD. 2014. The relationship between sexual selection and sexual conflict. Cold Spring Harb Perspect Biol doi: 10.1101/acshperspect.a017517.

Kokko H, Klug H, Jennions MD. 2012. Unifying cornerstones of sexual selection: Operational sex ratio, Bateman gradient and the scope for competitive investment. Ecol Lett 15: 1340-1351.

Klug H, Bonsall MB, Alonzo SH. 2013a. The origin of parental care in relation to male and female life history. Ecol Evol 3: 779-791.

Klug H, Bonsall MB, Alonzo SH. 2013b. Sex differences in life history drive evolutionary transitions among maternal, paternal, and bi-parental care. Ecol Evol 3: 792-806.

Lande R. 1981. Models of speciation by sexual selection on polygenic traits. Proc Natl Acad Sci 78: 3721-3725.

Lehtonen J, Kokko H. 2011. Two roads to two sexes: Unifying gamete competition and gamete limitation in a single model of anisogamy evolution. Behav Ecol Sociobiol 65: $445-459$.

Lessells CM, Snook RR, Hosken DJ. 2009. The evolutionary origin and maintenance of sperm: Selection for a small, motile gamete mating type. In Sperm biology: An evolutionary perspective (ed. Birkhead TR, Hosken D, Pitnick S), pp. 43-67. Academic, London.

Levitan DR. 1996. Effects of gamete traits on fertilization in the sea and the evolution of sexual dimorphism. Nature 382: $153-155$.

Levitan DR. 2005. The distribution of male and female reproductive success in a broadcast spawning marine invertebrate. Integr Comp Biol 45: 848-855.

Levitan DR. 2010. Sexual selection in external fertilizers. In Evolutionary behavioral ecology (ed. Westneat DF, Fox CW), pp. 365-378. Oxford University Press, Oxford.

Levitan DR, Petersen C. 1995. Sperm limitation in the sea. Trends Ecol Evol 10: 228-231.

Maynard Smith J. 1958. Sexual selection. In A century of Darwin (ed. Barnet SA), pp. 230-244. Heineman, London.

Maynard Smith J. 1977. Parental investment: A prospective analysis. Anim Behav 25: 1-9.

Maynard Smith J. 1978. The evolution of sex. Cambridge University Press, Cambridge.

Maynard Smith J. 1982. Evolution and the theory of games. Cambridge University Press, Cambridge.

Maynard Smith J, Price GR. 1973. The logic of animal conflicts. Nature 246: 15-18.

Maynard Smith J, Szathmáry E. 1995. The major transitions in evolution. Freeman Spektrum, Oxford.

O'Donald P. 1962. The theory of sexual selection. Heredity 17: $541-552$.

O’Donald P. 1980. Genetic models of sexual selection. Cambridge University Press, Cambridge.

Orians GH. 1969. On the evolution of mating systems in birds and mammals. Am Nat 103: 589-603.

Parker GA. 1970. Sperm competition and its evolutionary consequences in the insects. Biol Rev 45: 525-567.

Parker GA. 1978a. Searching for mates. In Behavioural ecology: An evolutionary approach (ed. Krebs JR, Davies NB), pp. 214-244. Blackwell, Oxford.
Parker GA. 1978b. Selfish genes, evolutionary games, and the adaptiveness of behaviour. Nature 274: 849-855.

Parker GA. 1978c. Selection on non-random fusion of gametes during the evolution of anisogamy. J Theor Biol 73: $1-28$.

Parker GA. 1979. Sexual selection and sexual conflict. In Sexual selection and reproductive competition in insects (ed. Blum MS, Blum NA), pp. 123-166. Academic, New York.

Parker GA. 1982. Why are there so many tiny sperm? Sperm competition and the maintenance of two sexes. J Theor Biol 96: 281-294.

Parker GA. 1984. Sperm competition and the evolution of animal mating strategies. In Sperm competition and the evolution of animal mating systems (ed. Smith RL), pp. 1-60. Academic, Orlando, FL.

Parker GA. 2006a. Behavioural ecology: The science of natural history. In Essays on animal behaviour: Celebrating 50 years of animal behaviour (ed. Lucas JR, Simmons LW), pp. 23-56. Elsevier, Burlington, MA.

Parker GA. 2006b. Sexual conflict over mating and fertilization: An overview. Phil Trans R Soc B 361: 235-259.

Parker GA. 2010. Reflections at dusk. In Leaders in animal behavior: The second generation (ed. Drickamer L, Dewsbury DA), pp. 429-464. Cambridge University Press, Cambridge.

Parker GA. 2011. The origin and maintenance of two sexes (anisogamy), and their gamete sizes by gamete competition. In The evolution of anisogamy: A fundamental phenomenon underlying sexual selection (ed. Togashi $\mathrm{T}$, Cox PA), pp. 17-74. Cambridge University Press, Cambridge.

Parker GA. 2013. A personal history of the development of animal contest theory and its role in the 1970s. In Animal contests (ed. Hardy ICW, Briffa M), pp. xi-xx. Cambridge University Press, Cambridge.

Parker GA, Birkhead TR. 2013. Polyandry: The history of a revolution. Phil Trans R Soc B 368: 20120335.

Parker GA, Partridge L. 1998. Sexual conflict and speciation. Phil Trans R Soc B 353: 261-274.

Parker GA, Pizzari T. 2010. Sperm competition and ejaculate economics. Biol Rev 85: 897-934.

Parker GA, Pizzari T. Sexual selection: The logical imperative. In Current perspectives on sexual selection: What's left after Darwin (ed. Houquet T). Springer, Berlin (in press).

Parker GA, Baker RR, Smith VGF. 1972. The origin and evolution of gamete dimorphism and the male-female phenomenon. J Theor Biol 36: 529-553.

Parker GA, Lessells CM, Simmons LW. 2013. Sperm competition games: A general model for pre-copulatory malemale competition. Evolution 67: 95-109.

Partridge L, Fowler K, Trevitt S, Sharp W. 1986. An examination of the effects of males on the survival and eggproduction rates of female Drosophila melanogaster. J Insect Physiol 11: 925-929.

Queller DC. 1997. Why do females care more than males? Proc R Soc Lond B 264: 1555-1557.

Rice WR. 1984. Sex chromosomes and the evolution of sexual dimorphism. Evolution 38: 735-742. 


\section{G.A. Parker}

Rice WR. 1992. Sexually antagonistic genes: Experimental evidence. Science 256: 1436-1439.

Rice WR. 1996. Sexually antagonistic male adaptation triggered by experimental arrest of female evolution. Nature 361: 232-234.

Rice WR, Holland B. 1997. The enemies within: Intergenomic conflict, interlocus contest evolution (ICE), and the intraspecific Red Queen. Behav Ecol Sociobiol 41: $1-10$.

Richards OW. 1927. Sexual selection and allied problems in the insects. Biol Rev 2: 298-364.

Rowe L. 1992. Convenience polyandry in a water strider: Foraging conflicts and female control of copulation frequency and guarding duration. Anim Behav 44: 189202.

Rowe L, Arnqvist G, Krupa J, Sih A. 1994. Sexual conflict and the evolutionary ecology of mating patterns: Water striders as a model system. Trends Ecol Evol 9: 289-293.

Run J-Q, Chen C-P, Chang K-H, Chia F-S. 1988. Mating behaviour and reproductive cycle of Archaster typicus (Echinodermata: Asteroidea). Mar Biol 99: 247-253.

Schärer L, Rowe L, Arnqvist G. 2012. Anisogamy, chance and the evolution of sex roles. Trends Ecol Evol 27: $260-264$.

* Schärer L, Janicke T, Ramm SA. 2014. Sexual conflict in hermaphrodites. Cold Spring Harb Perspect Biol doi: 10.1101/cshperspect.a017673.

Scudo FM. 1967. The adaptive value of sexual dimorphism: I. Anisogamy. Evolution 21: 285-291.

Shuster SM, Wade MJ. 2003. Mating systems and strategies. Princeton University Press, Princeton, NJ.

Simmons LW. 2001. Sperm competition and its evolutionary consequences in the insects. Princeton University Press, Princeton, NJ.
Simmons LW, Fitzpatrick JL. 2012. Sperm wars and the evolution of male fertility. Reproduction 144, 519-534.

Slattery M, Bosch I. 1993. Mating behavior of a brooding antarctic asteroid, Neosmilaster georgianus. Invertebr Reprod Dev 24: 97-102.

Smith RL, ed. 1984. Sperm competition and the evolution of animal mating systems. Academic, New York.

Stockley P. 1997. Sexual conflict resulting from adaptations to sperm competition. Trends Ecol Evol 12: 154-159.

Stockley P, Gage MJG, Parker GA, Møller AP. 1997. Sperm competition in fish: The evolution of testis size and ejaculate characteristics. Am Nat 149: 933-954.

* Székely T. 2014. Sexual conflict between parents: Offspring desertion and asymmetrical parental care. Cold Spring Harb Perspect Biol doi: 10.1101/cshperspect. a017665.

Thornhill R. 1983. Cryptic female choice and its implications in the scorpionfly Harpobittacus nigriceps. Am Nat 122: $765-788$.

Tregenza T, Wedell N, Chapman T. 2006. Introduction. Sexual conflict: A new paradigm? Phil Trans R Soc B 361: 229-234.

Trivers R. 1972. Parental investment and sexual selection. In Sexual selection and the descent of man 1871-1971 (ed. Campbell B), pp. 139-179. Aldine, Chicago.

West SA. 2009. Sex allocation. Princeton University Press, Princeton, NJ.

Williams GC. 1966. Adaptation and natural selection. Princeton University Press, Princeton, NJ.

Williams GC. 1975. Sex and evolution. Princeton University Press, Princeton, NJ.

Zahavi A. 1975. Mate selection-A selection for a handicap. J Theor Biol 53: 205-214.

Zeh JA. 2004. Sexy sons: A dead end for cytoplasmic genes. Proc R Soc B 271: S306-S309. 


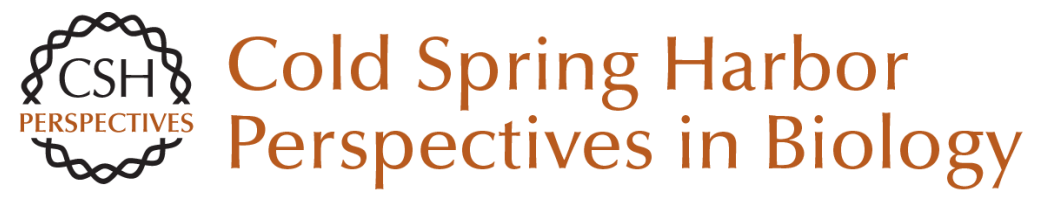

\section{The Sexual Cascade and the Rise of Pre-Ejaculatory (Darwinian) Sexual Selection, Sex Roles, and Sexual Conflict}

Geoff A. Parker

Cold Spring Harb Perspect Biol 2014; doi: 10.1101/cshperspect.a017509 originally published online August 21, 2014

Subject Collection The Genetics and Biology of Sexual Conflict

Mechanisms and Evidence of Genital

Coevolution: The Roles of Natural Selection, Mate

Choice, and Sexual Conflict

Patricia L.R. Brennan and Richard O. Prum

The Evolution of Sexually Antagonistic

Phenotypes

Jennifer C. Perry and Locke Rowe

Reproductive Parasitism: Maternally Inherited

Symbionts in a Biparental World

Gregory D.D. Hurst and Crystal L. Frost

Sex-Biased Gene Expression and Sexual Conflict throughout Development

Fiona C. Ingleby, Ilona Flis and Edward H. Morrow

Human Homosexuality: A Paradigmatic Arena for

Sexually Antagonistic Selection?

Andrea Camperio Ciani, Umberto Battaglia and Giovanni Zanzotto

Sexual Conflict Arising from Extrapair Matings in Birds

Alexis S. Chaine, Robert Montgomerie and Bruce E. Lyon

Sexual Conflict and Seminal Fluid Proteins: A Dynamic Landscape of Sexual Interactions

Laura K. Sirot, Alex Wong, Tracey Chapman, et al.
Infanticide as Sexual Conflict: Coevolution of

Male Strategies and Female Counterstrategies Ryne A. Palombit

Copulatory Wounding and Traumatic

Insemination

Klaus Reinhardt, Nils Anthes and Rolanda Lange

Sexual Conflict in Hermaphrodites

Lukas Schärer, Tim Janicke and Steven A. Ramm

Sexual Conflict and Sperm Competition

Dominic A. Edward, Paula Stockley and David J. Hosken

Sexually Antagonistic Zygotic Drive: A New Form of Genetic Conflict between the Sex

Chromosomes

Urban Friberg and William R. Rice

Sex Chromosome Drive

Quentin Helleu, Pierre R. Gérard and Catherine Montchamp-Moreau

Is Sexual Conflict an "Engine of Speciation"? Sergey Gavrilets

For additional articles in this collection, see http://cshperspectives.cshlp.org/cgi/collection/

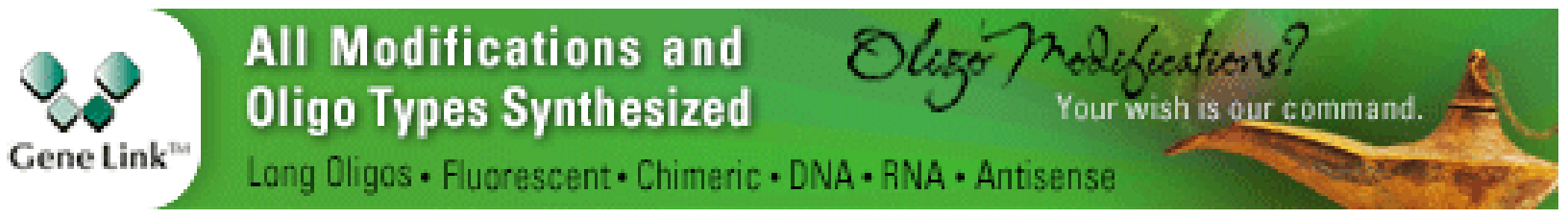

Copyright @ 2014 Cold Spring Harbor Laboratory Press; all rights reserved 
Conflict on the Sex Chromosomes: Cause, Effect, and Complexity

Judith E. Mank, David J. Hosken and Nina Wedell
Sexual Cannibalism as a Manifestation of Sexual

Conflict

Jutta M. Schneider

For additional articles in this collection, see http://cshperspectives.cshlp.org/cgi/collection/

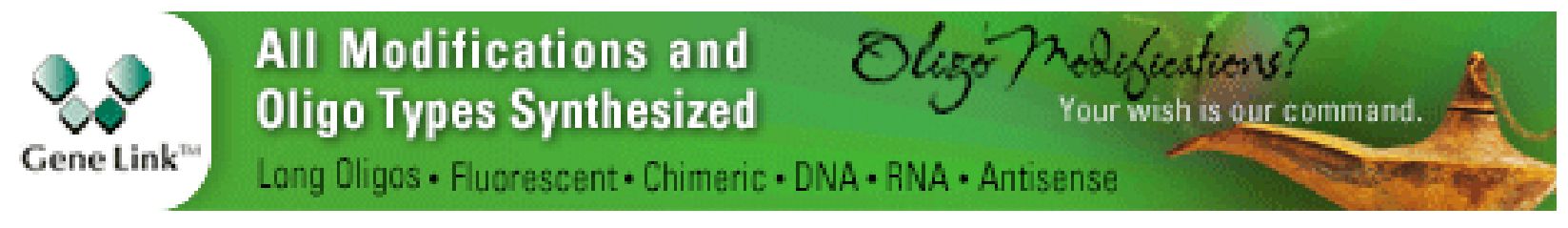

Copyright @ 2014 Cold Spring Harbor Laboratory Press; all rights reserved 